\title{
In vitro antibiofilm activity of resveratrol against avian pathogenic Escherichia coli
}

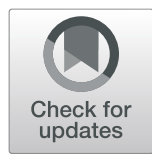

Xiangchun Ruan ${ }^{1,2^{*}}$, Xiaoling Deng ${ }^{1}$, Meiling Tan ${ }^{1}$, Chengbo Yu', Meishi Zhang ${ }^{1}$, Ying Sun ${ }^{1}$ and Nuohao Jiang ${ }^{1}$

\begin{abstract}
Background: Avian pathogenic Escherichia coli (APEC) strains cause infectious diseases in poultry. Resveratrol is extracted from Polygonum cuspidatum, Cassia tora Linn and Vitis vinifera, and displays good antimicrobial activity. The present study aimed to investigate the antibiofilm effect of resveratrol on APEC in vitro. The minimum inhibitory concentration (MIC) of resveratrol and the antibiotic florfenicol toward APEC were detected using the broth microdilution method. Then, the effect of resveratrol on swimming and swarming motility was investigated using a semisolid medium culture method. Subsequently, the minimum biofilm inhibitory concentration (MBIC) and the biofilm eradication rate were evaluated using crystal violet staining. Finally, the antibiofilm activity of resveratrol was observed using scanning electron microscopy (SEM). Meanwhile, the effects of florfenicol combined with resveratrol against biofilm formation by APEC were evaluated using optical microscopy (OM) and a confocal laser scanning microscopy (CLSM).

Results: The MICs of resveratrol and florfenicol toward APEC were $128 \mu \mathrm{g} / \mathrm{mL}$ and $64 \mu \mathrm{g} / \mathrm{mL}$, respectively. The swimming and swarming motility abilities of APEC were inhibited in a resveratrol dose-dependent manner. Furthermore, resveratrol showed a significant inhibitory activity against APEC biofilm formation at concentrations above $1 \mu \mathrm{g} / \mathrm{mL}(p<0.01)$. Meanwhile, the inhibitory effect of resveratrol at $32 \mu \mathrm{g} / \mathrm{mL}$ on biofilm formation was observed using SEM. The APEC biofilm was eradicated at $32 \mu \mathrm{g} / \mathrm{mL}$ of resveratrol combined with $64 \mu \mathrm{g} / \mathrm{mL}$ of florfenicol, which was observed using CLSM and OM. Florfenicol had a slight eradication effect of biofilm formation, whereas resveratrol had a strong biofilm eradication effect toward APEC.
\end{abstract}

Conclusion: Resveratrol displayed good antibiofilm activity against APEC in vitro, including inhibition of swimming and swarming motility, biofilm formation, and could eradicate the biofilm.

Keywords: Resveratrol, Avian pathogenic Escherichia coli, Biofilm, Antibiofilm activity

\section{Background}

Avian pathogenic Escherichia coli (APEC) causes localized and systemic avian infections, which are responsible for considerable economic losses in the poultry industry [1]. Like many bacteria, APEC can live in two different forms, a planktonic state and a biofilm state [2]. APEC

\footnotetext{
* Correspondence: ranxiangchun@163.com

'Laboratory of Veterinary Pharmacology and Toxicology, College of Animal Science and Technology, Anhui Agricultural University, 130 West Changjiang Road, Hefei 230036, Anhui Province, China

${ }^{2}$ Anhui Province Key Laboratory of Veterinary Pathobiology and Disease Control, Hefei 230036, Anhui Province, China
}

can form a single or multi-layer biofilm [3], which utilizes components of the extracellular polymeric substance (EPS). The main components of EPS include polysaccharides, proteins, nucleic acids, lipids, pili, and flagella [4]. Biofilm formation is one of the main mechanisms by which APEC develops drug resistance. It is difficult for antibiotics to invade the multilayer structure of the APEC biofilm and reach the cells to exert their effects [5]. Therefore, APEC in the form of biofilms often cause chronic, persistent, and repeated infections in the clinic, making treatment difficult $[6,7]$. Biofilm formation has been linked to several reports of human and

(c) The Author(s). 2021 Open Access This article is licensed under a Creative Commons Attribution 4.0 International License, which permits use, sharing, adaptation, distribution and reproduction in any medium or format, as long as you give appropriate credit to the original author(s) and the source, provide a link to the Creative Commons licence, and indicate if changes were made. The images or other third party material in this article are included in the article's Creative Commons licence, unless indicated otherwise in a credit line to the material. If material is not included in the article's Creative Commons licence and your intended use is not permitted by statutory regulation or exceeds the permitted use, you will need to obtain permission directly from the copyright holder. To view a copy of this licence, visit http://creativecommons.org/licenses/by/4.0/. The Creative Commons Public Domain Dedication waiver (http://creativecommons.org/publicdomain/zero/1.0/) applies to the data made available in this article, unless otherwise stated in a credit line to the data. 
animal infectious diseases, as well as food source contamination $[8,9]$.

Biofilm formation can be divided into five stages: planktonic motility and reversible attachment; monolayer colony formation and permanent attachment; microcolony formation of flat structures; macrocolony formation of mushroom-like structures; and dispersion and reattachment [10]. Colonization and adhesion play an important role in biofilm formation [11]. Motility is necessary for colonization, adhesion, and infection of pathogens. Escherichia coli requires motility to colonize the host successfully and cause pathogenic infections. Flagella-mediated swimming and swarming motility are the main movement modes of E. coli [7]. To respond to, and cope with, a wide range of external conditions, $E$. coli must sense and respond quickly to external signals. $E$. coli flagellar motility is dependent upon the environment ( $\mathrm{pH}$ and salt concentration), which are an essential part of the induction of adhesion on a host surface to enable biofilm formation [12]. Motility plays a critical role in the primary interaction with a surface and can promote E. coli biofilm development [13].

Natural products that inhibit and eradicate bacterial biofilms have been explored [14-16]. The natural product, resveratrol (trans - 3, 4, 5-trihydroxystilbene $\left.\left(\mathrm{C}_{14} \mathrm{H}_{12} \mathrm{O}_{3}\right)\right)$, exists in a variety of plants, such as Polygonum cuspidatum, Cassia tora Linn, and Vitis vinifera. It has a good health benefits, including antimicrobial, anti-inflammatory, anti-cancer, cardiovascular, and neuroprotective activities $[17,18]$. The inhibitory activities of resveratrol toward bacteria $[19,20]$, fungi [21], and viruses [22, 23] have been reported. Meanwhile, the antibiofilm activity of resveratrol has been demonstrated via its inhibition of biofilm formation, eradication of biofilms [24], and inhibition of motility [25]. However, reports of its antibiofilm effect in vitro against clinically isolated APEC are limited. The present study aimed to investigate effects of resveratrol on the inhibition and eradication of APEC biofilms.

\section{Methods}

\section{Chemicals and strain}

Resveratrol was purchased from MedChemExpress (Monmouth Junction, NJ, USA). The resveratrol batch number was 58,706, and its purity (as assessed using liquid chromatography-mass spectrometry) was $99.70 \%$. The antibiotic florfenicol was purchased from Hansyn Pharma (Jiangsu, China; 98\% purity). The wild-type APEC strain was generously donated by Professor Li (The Livestock and Poultry Disease Diagnostic Centre of Anhui Agricultural University) and the intralaboratory serial number 11-28-2 was assigned to the strain. The strain was isolated aseptically from the livers of infected chickens.

\section{Minimum inhibitory concentration (MIC) determination and growth curve assay}

The MICs toward APEC of resveratrol and florfenicol were detected using the broth microdilution method according to the American Committee for Clinical and Laboratory Standards Institute methods (CLSI). Briefly, $100 \mu \mathrm{L}$ of resveratrol or florfenicol was added to the wells of 96-well U-bottomed plates using two-fold serial dilutions in Mueller-Hinton (MH) broth ( $\mathrm{pH}$ 7.2-7.4). The final concentration ranged from $0.5 \mu \mathrm{g} / \mathrm{mL}$ to $256 \mu \mathrm{g} / \mathrm{mL}$. APEC was cultured to the logarithmic growth stage. The culture was adjusted to $\mathrm{OD}_{600}=0.1$ $\left(1 \times 10^{8} \mathrm{CFU} / \mathrm{mL}\right)$, and then it was diluted 100 times to $1 \times 10^{6} \mathrm{CFU} / \mathrm{mL}$. Thereafter, each well was inoculated with $100 \mu \mathrm{L}$ of the APEC inoculum $\left(1 \times 10^{6} \mathrm{CFU} / \mathrm{mL}\right)$ and cultured statically at $37^{\circ} \mathrm{C}$ for $18-24 \mathrm{~h}$. Meanwhile, $\mathrm{MH}$ broth as the negative control group and the APEC inoculum as the positive control were prepared, with three wells for each treatment as parallel samples.

To determine the growth curve, overnight cultures $(200 \mu \mathrm{L})$ of APEC were added to $100 \mathrm{~mL}$ of fresh LuriaBertani (LB) broth. The suspension was supplemented with resveratrol at a final concentration of 1/32 MIC, 1/ $16 \mathrm{MIC}, 1 / 8 \mathrm{MIC}, 1 / 4 \mathrm{MIC}$, and $1 / 2 \mathrm{MIC}$, respectively and incubated at $37^{\circ} \mathrm{C}$ with constant shaking $(200 \mathrm{rpm})$. At $0,2,4,6,8,10,12,14,16,18,20,22$, and $24 \mathrm{~h}, 3 \mathrm{~mL}$ of each sample was obtained, and the turbidity was measured at $600 \mathrm{~nm}$ using a spectrophotometer (UV-5100, Metash, Shanghai, China). The growth curve was constructed by plotting the absorbance versus the incubation time [26].

\section{Determining the maturation time of biofilm formation}

Two hundred microliters of APEC culture $\left(\mathrm{OD}_{600}=\right.$ 0.01 ) were added to the wells of a 96-well plate and incubated at $37^{\circ} \mathrm{C}$ for $0.5,1,2,3,4,5,6$, and 7 days, and the LB culture medium was changed every day. The blank control was LB nutrient broth, and each well was repeated four times as parallel samples. The planktonic bacteria were washed off using sterile phosphate-buffered saline (PBS). Each well was fixed with $200 \mu \mathrm{L}$ of methanol for $15 \mathrm{~min}$ and dried naturally after removing the methanol. The formed biofilms were stained using $200 \mu \mathrm{L}$ of crystal violet for 20 min. After removing the crystal violet, each well was washed three times with PBS. Then, $200 \mu \mathrm{L} 33 \%$ acetic acid was added to the well and incubated for $30 \mathrm{~min}$. The absorbance was measured at $570 \mathrm{~nm}$ using a Microplate Reader (Sunrise, Tecan, Switzerland) to determine the biomass of the biofilm. The definition of the different stages of APEC biofilm formation was based on description of the biofilm growth curve by $\mathrm{Yu}$ et al. [27]. 


\section{Motility assay}

Swimming and swarming motility were investigated on semisolid culture medium in plates [26, 28]. LB medium was supplemented with $0.3 \%$ agar and $0.5 \%$ glucose for the swimming motility assay, and with $0.5 \%$ glucose and $0.5 \%$ agar for the swarming motility assay. Resveratrol was added to the LB medium at final concentrations of $1 / 32 \mathrm{MIC}$ to $1 / 2 \mathrm{MIC}$. Thereafter, $2 \mu \mathrm{L}$ of APEC culture $\left(\mathrm{OD}_{600}=1\right)$ was placed on the center of the culture plates and incubated at $37^{\circ} \mathrm{C}$ for $24 \mathrm{~h}$. The tests were repeated three times.

\section{Minimum biofilm inhibitory concentration (MBIC) assay}

The MBIC assay was performed as previously described with appropriate modifications [29, 30]. Briefly, the APEC culture was added with different concentrations of resveratrol (0, 1/128 MIC, 1/64 MIC, 1/32 MIC, 1/16 $\mathrm{MIC}, 1 / 8 \mathrm{MIC}, 1 / 4 \mathrm{MIC}$, and 1/2 MIC, corresponding to $0,1,2,4,8,16,32$, and $64 \mu \mathrm{g} / \mathrm{mL}$, respectively). After incubation at $37^{\circ} \mathrm{C}$ for $24 \mathrm{~h}$, the planktonic cells were discarded, and the adherent cells were washed three times with PBS. Crystal violet staining was then performed as described in "Determining the maturation time of biofilm formation". The absorbance was detected at $570 \mathrm{~nm}$ using a Microplate Reader. The inhibition rate was calculated in comparison with the positive control $(0 \mu \mathrm{g} /$ $\mathrm{mL}$ resveratrol) [31]. The inhibition rate $=(\mathrm{OD}$ positive $\mathrm{OD}_{\text {test }}$ ) / OD positive $* 100 \%$. Each experimental well was repeated four times.

\section{Biofilm inhibition analysis using scanning Electron microscopy (SEM)}

The inhibitory effect of resveratrol on APEC biofilm formation was observed using SEM [32]. The slides $(\Phi=$ $10 \mathrm{~mm}$ ), as adhesion carriers for the biofilm, were placed into 24-well plates. Then, $0.5 \mathrm{~mL}$ of APEC suspension $\left(\mathrm{OD}_{600}=0.01\right)$ and $0.5 \mathrm{~mL}$ different concentrations of resveratrol (0, 1/32 MIC, 1/16 MIC, 1/8 MIC, 1/4 MIC, and $1 / 2 \mathrm{MIC}$ ) were added to the wells, which were incubated statically at $37^{\circ} \mathrm{C}$ for $48 \mathrm{~h}$. The slides were rinsed three times with PBS and fixed with $5 \%$ glutaraldehyde at $4{ }^{\circ} \mathrm{C}$ for $12 \mathrm{~h}$. The samples were dehydrated with a graded series of ethanol/water mixtures $(30,50,60,70$, 80,90 , and $100 \%$ ) at each concentration for $20 \mathrm{~min}$, and dehydrated in $100 \%$ acetone twice. Finally, the biofilm sample was assessed under a scanning electron microscope (S-4800, Hitachi, Tokyo, Japan) [33].

\section{Biofilm eradication analysis \\ Biofilm eradication rate}

The APEC culture $\left(\mathrm{OD}_{600}=0.01\right)$ was incubated in a 96well plate at $37^{\circ} \mathrm{C}$ for $36 \mathrm{~h}$. The planktonic cells were removed, and the attached biofilm cells were washed three times with fresh LB broth. The attached biofilm cells were treated with florfenicol (MIC) and resveratrol $(0,1 /$ $32 \mathrm{MIC}, 1 / 16 \mathrm{MIC}, 1 / 8 \mathrm{MIC}, 1 / 4 \mathrm{MIC}$, and 1/2 MIC, respectively). After incubation at $37^{\circ} \mathrm{C}$ for $24 \mathrm{~h}$, the planktonic cells were discarded, and the adherent cells were washed three times with PBS. Crystal violet staining was then performed as described in "Determining the maturation time of biofilm formation". The absorbance was detected at $570 \mathrm{~nm}$ using a Microplate Reader and the eradication rate was calculated in comparison with the control [31]. Each well was repeated six times.

\section{Optical microscopy (OM) observation}

One milliliter of APEC suspension $\left(\mathrm{OD}_{600}=0.01\right)$ was added to each well containing a sterile slide in a 24-well plate in advance and incubated statically at $37^{\circ} \mathrm{C}$ for 36 h. After washing three times with fresh LB broth, florfenicol (MIC) and resveratrol (0, 1/32 MIC, 1/16 MIC, 1/8 MIC, $1 / 4 \mathrm{MIC}$, and 1/2 MIC, respectively) were added to the LB broth. After $24 \mathrm{~h}$ of treatment, the slides were washed with PBS, fixed with methanol for $15 \mathrm{~min}$, and then stained with crystal violet. The slides were washed gently with PBS until the eluent was colorless. Finally, eradication of the biofilm was observed under an optical microscope (BA210, Motic, Xiamen, China) [34].

\section{Confocal laser scanning microscopy (CLSM) observation}

APEC biofilm culture and florfenicol and resveratrol treatment were the same as those described in the OM assay. The slides were washed gently with PBS and stained with the fluorescent dyes CFDA SE (5-(and 6)Carboxyfluorescein diacetate, succinimidyl ester) and PI (Propidium Iodide). After incubation at $25^{\circ} \mathrm{C}$ for $15 \mathrm{~min}$, the slides were captured at excitation/emission wavelengths of $535 / 617 \mathrm{~nm}$ for PI, and $485 / 520 \mathrm{~nm}$ for CFDA SE using a confocal laser scanning microscope (FV1000, Olympus, Tokyo, Japan) [35].

\section{Statistical analysis}

The data were expressed as the mean \pm SD. The statistical differences among the different groups were compared using one-way analysis of variance (ANOVA), significant means were separated using Tukey's Honest significant difference, and statistical significance was accepted at $p<0.05$.

\section{Results}

\section{MIC determination and growth curve construction}

The MICs of resveratrol and florfenicol against planktonic APEC were $128 \mu \mathrm{g} / \mathrm{mL}$ and $64 \mu \mathrm{g} / \mathrm{mL}$, respectively. Resveratrol had little effect on APEC growth at the $1 / 32$ MIC, 1/16 MIC, 1/8 MIC, 1/4 MIC, and 1/2 MIC, which corresponded to concentrations of $4,8,16,32$, and $64 \mu \mathrm{g} / \mathrm{mL}$, respectively (Fig. 1). 


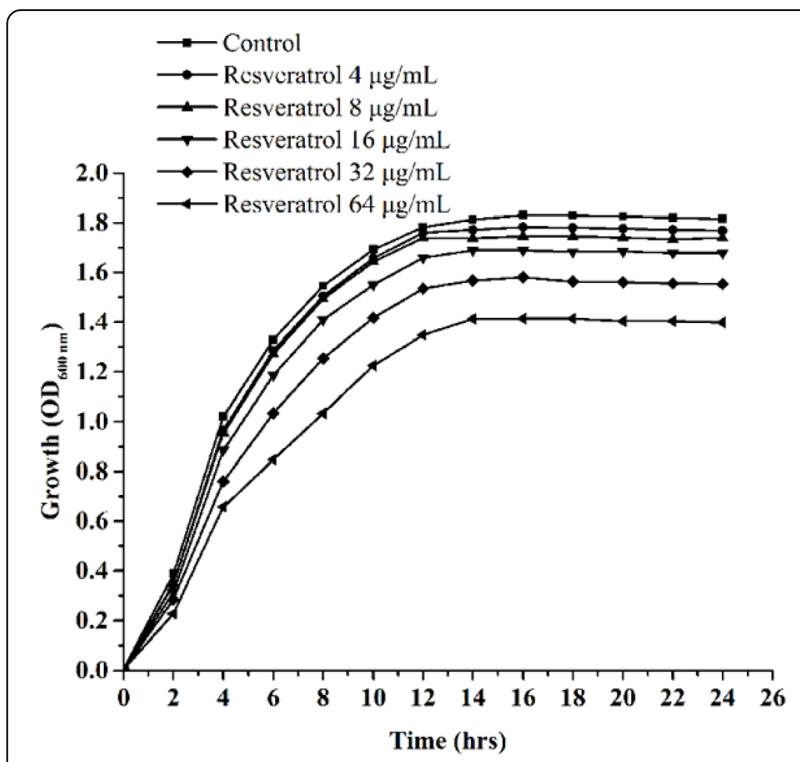

Fig. 1 Growth curves of the avian pathogenic Escherichia coli strain under different concentrations of resveratrol

\section{Biofilm maturation time}

The biofilm formation of APEC is a dynamic process, comprising colonization, accumulation, maturation, shedding, and replantation stages. The complete process of biofilm formation took 4 days. The initial adhesion was completed after incubation for $12 \mathrm{~h}$. The biofilm was formed at 1 day and matured at 2 days. The mature biofilm began to fall off from 2 to $4 \mathrm{~d}$; and then the biofilm formation entered the next growth cycle (Fig. 2).

\section{Motility assay}

The effects of resveratrol on the swimming and swarming motility of APEC were evaluated (Fig. 3). With increasing resveratrol concentration, the swimming motility ability of APEC decreased gradually. The same

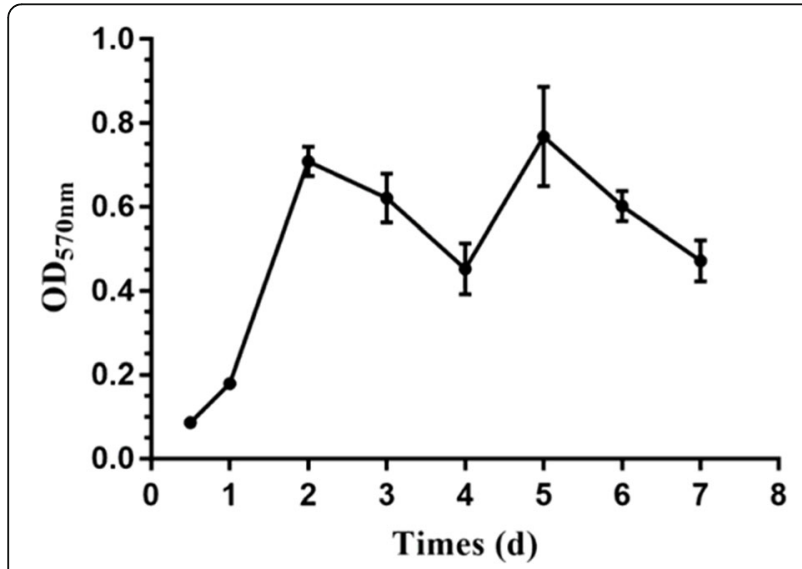

Fig. 2 Curve showing the dynamics of biofilm formation by the avian pathogenic Escherichia coli result was found in the swarming motility assay. Thus, the inhibitory effect of resveratrol on APEC motility occurred in a dose-dependent manner.

of avian pathogenic Escherichia coli.

\section{MBIC assay}

Resveratrol had a strong inhibitory effect on the biofilm formation of APEC. Resveratrol inhibited biofilm formation significantly $(p<0.01)$ at $1 \mu \mathrm{g} / \mathrm{mL}(1 / 128 \mathrm{MIC})$, and the biofilm inhibition rate reached $31.66 \%$. Biofilm formation was inhibited significantly at $4 \mu \mathrm{g} / \mathrm{mL}$ compared with that at 1 and $2 \mu \mathrm{g} / \mathrm{mL}$ of resveratrol $(p<0.01)$, and the inhibition rate reached $75.61 \%$. The inhibitory effect of resveratrol on APEC biofilm formation also occurred in a dose-dependent manner (Fig. 4).

\section{Observation of biofilm inhibition using SEM}

The inhibitory effect of resveratrol on APEC biofilm formation was observed using SEM. The APEC cells adhered tightly and formed a dense biofilm on the control slides. The biofilm decreased and became sparse on the slides after resveratrol treatment at $4 \mu \mathrm{g} / \mathrm{mL}$. When the resveratrol concentration increased from $4 \mu \mathrm{g} / \mathrm{mL}$ to $16 \mu \mathrm{g} / \mathrm{mL}$, APEC biofilm formation was inhibited increasingly on the slides. At a resveratrol concentration of $32 \mu \mathrm{g} / \mathrm{mL}$, only a few APECs adhered to the slides, and at $64 \mu \mathrm{g} / \mathrm{mL}$, scattered or individual APEC cells were observed on the slides (Fig. 5).

\section{Biofilm eradication analysis}

In the absence of resveratrol $(0 \mu \mathrm{g} / \mathrm{mL})$, the eradication rate by florfenicol on the biofilm was $16.74 \%$ at $64 \mu \mathrm{g} /$ $\mathrm{mL}$ (MIC). Meanwhile, in presence of florfenicol at $64 \mu \mathrm{g} / \mathrm{mL}$, the eradication rate of biofilm increased gradually with increasing resveratrol concentration. When the concentration of resveratrol reached $16 \mu \mathrm{g} / \mathrm{mL}$ and $32 \mu \mathrm{g} / \mathrm{mL}$, the eradication rates of biofilm were 55 and $73 \%$, respectively. Furthermore, the eradication rate of biofilm exceeded $99 \%$ at a resveratrol concentration of $64 \mu \mathrm{g} / \mathrm{mL}$ (Fig. 6A). These results revealed that florfenicol had a slight biofilm eradication effect at $64 \mu \mathrm{g} / \mathrm{mL}$. Comparatively, resveratrol at $32 \mu \mathrm{g} / \mathrm{mL}$ showed a strong biofilm eradication effect toward APEC.

Under CLSM observation, viable APEC cells with intact membranes were stained fluorescent green, whereas dead cells with damaged membranes were stained fluorescent red, and the coexistence of living and dead cells appeared yellow. A dense biofilm formed and living APEC cells were visible on the slides of the control (Fig. $6 \mathrm{~B}$, Left, 400×). The majority of APEC cells located in the outermost layer of the biofilm were dead after treatment with florfenicol alone at $64 \mu \mathrm{g} / \mathrm{mL}$. However, a tight and dense biofilm still existed on the slides. This indicated that florfenicol could not destroy the APEC 


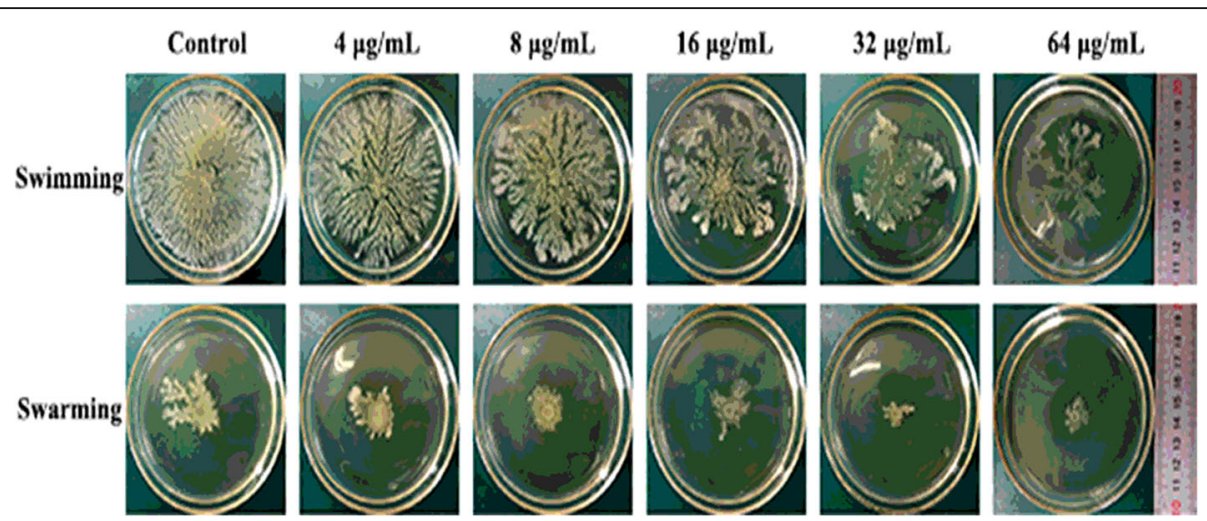

Fig. 3 Inhibitory effect of resveratrol on the swimming and swarming motility

biofilm (Fig. 6B, Left, 400×). As the resveratrol concentration increased from $4 \mu \mathrm{g} / \mathrm{mL}$ to $16 \mu \mathrm{g} / \mathrm{mL}$, the biofilm formed on the slides decreased gradually. The dense biofilm was destroyed and the number of large pieces of the biofilm decreased. Most of the APEC biofilm on the slides was eradicated after resveratrol treatment at $32 \mu \mathrm{g} / \mathrm{mL}$. Therefore, resveratrol has a strong eradication effect on the biofilm formed by APEC. Similar results were obtained using OM observation (Fig. 6B, Right, $100 \times)$.

\section{Discussion}

Clinical bacterial infectious diseases are very common, among which about $80 \%$ are related to bacterial biofilms [36]. A biofilm formed during infection is rarely eradicated by the host defense mechanisms. Bacterial adhesion and colonization play an important role in the process of biofilm formation. The pathogenicity of APEC

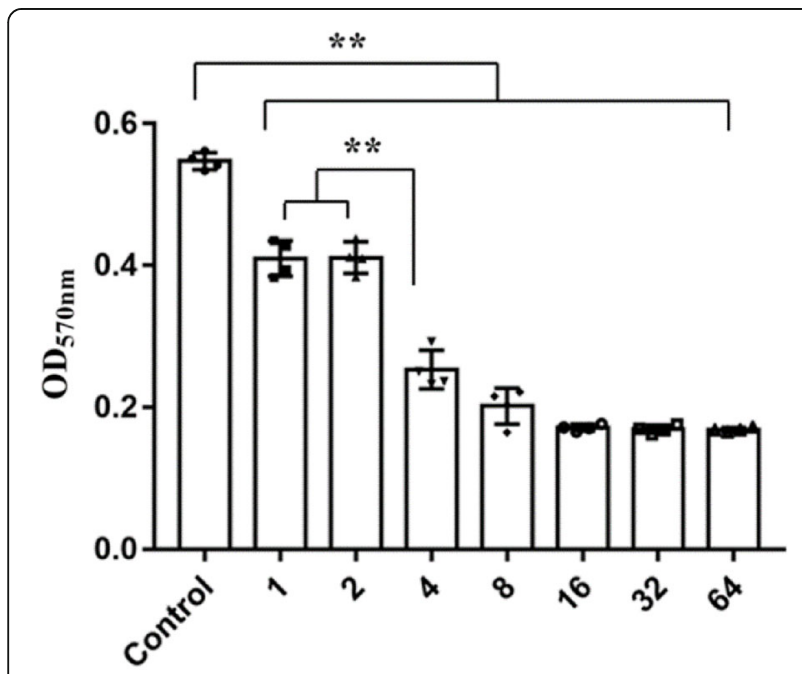

\section{Resveratrol $(\mu \mathrm{g} / \mathrm{mL})$}

Fig. 4 Inhibitory effect of resveratrol on avian pathogenic Escherichia coli biofilm formation (** $p<0.01$ ) is enhanced during the formation of a biofilm, which is caused by adhesion and colonization [37]. Some researchers believe that bacterial biofilms have nothing to do with pathogenicity in vivo [38]. However, the majority opinion suggests that bacterial biofilms are associated with pathogenicity in vivo. Most clinically isolated APECs have a strong or medium biofilm forming ability, which might be explain their high pathogenicity and difficult treatment [39]. It was reported that compared with planktonic cells, bacteria in the state of a biofilm can resist the host's immune defense [40]. Therefore, inhibiting the formation of APEC biofilms is of great significance in the clinical study of diseases caused by APEC.

Antibiotic therapy typically alleviates the symptoms caused by planktonic bacteria, but fails to kill bacteria in biofilms [6]. During aggravation of bacterial resistance, traditional Chinese medicines or their extracts have attracted attention. Plant-derived drugs have been applied widely in infection therapy because they are effective, safe, have low toxicity, and induce lower levels of acquired resistance [41-43]. Some compounds extracted from plants possess antibacterial and antibiofilm activities [44, 45]. Resveratrol, a natural product extracted from Polygonum cuspidatum, Cassia tora Linn, or Vitis vinifera, can inhibit and eradicate bacterial biofilms. The main antibiofilm activities of resveratrol comprise inhibiting the quorum sensing system, metabolism, and bacterial motility (chemotaxis) [46-49]. In the present study, resveratrol inhibited the formation of biofilms and destroyed formed biofilms in a dose-dependent manner. This was consistent with the results of resveratrol inhibition of biofilm formation by Fusobacterium nucleatum [47]. Resveratrol shows a strong antibiofilm activity toward APEC; thus, the mechanism of action of resveratrol on APEC biofilms should be further investigated.

Biofilm formation is affected by environmental factors, the contact surface, phylogeny, and two-component systems. Environmental factors include temperature, $\mathrm{pH}$, 


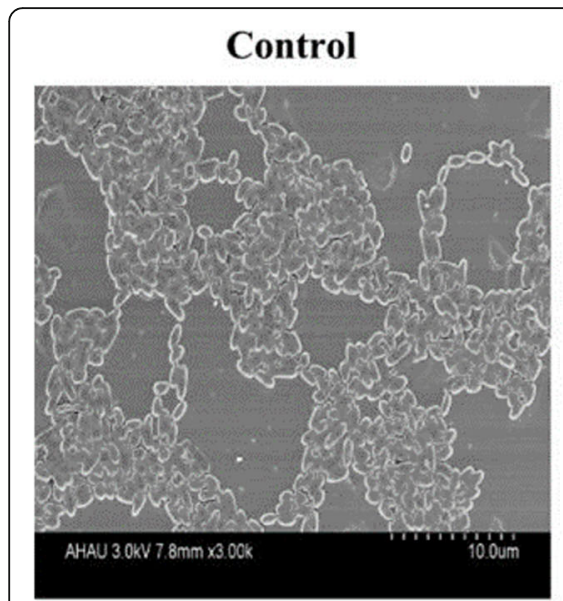

$16 \mu \mathrm{g} / \mathrm{mL}$

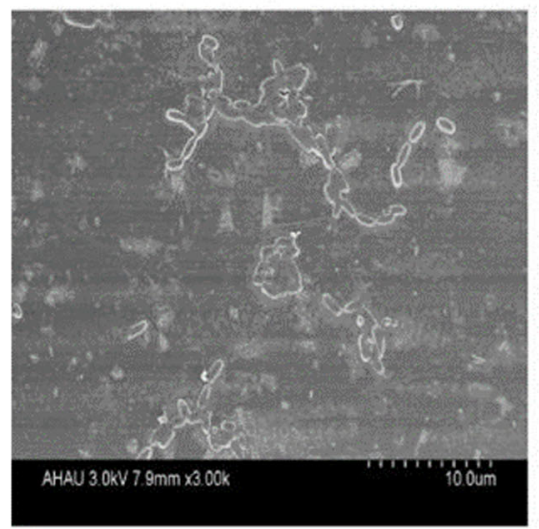

$4 \mu \mathrm{g} / \mathrm{mL}$

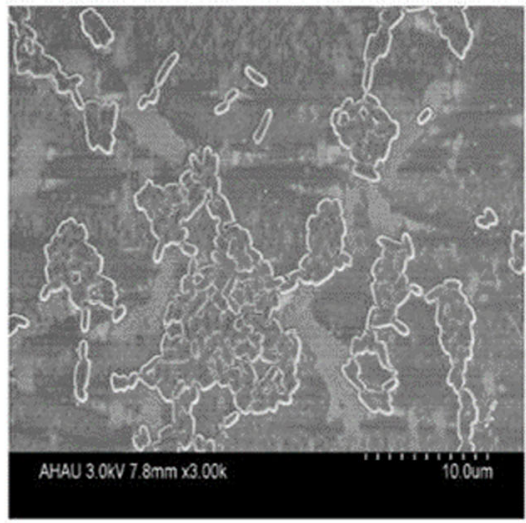

$32 \mu \mathrm{g} / \mathrm{mL}$

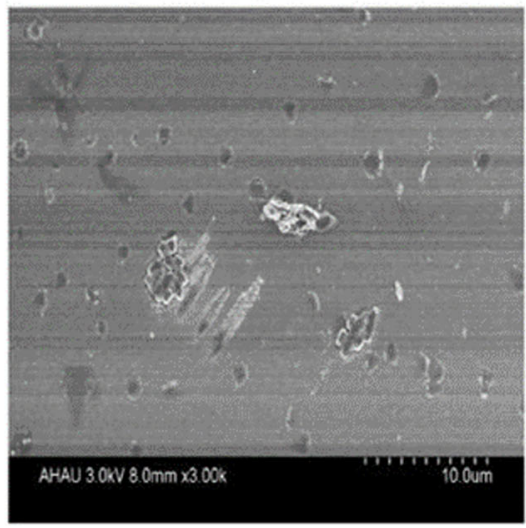

$8 \mu \mathrm{g} / \mathrm{mL}$

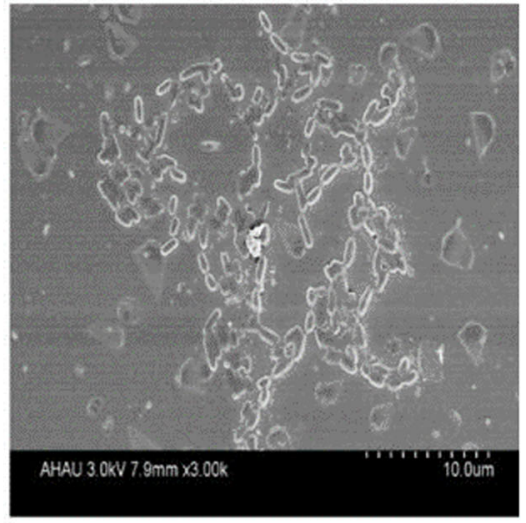

$64 \mu \mathrm{g} / \mathrm{mL}$

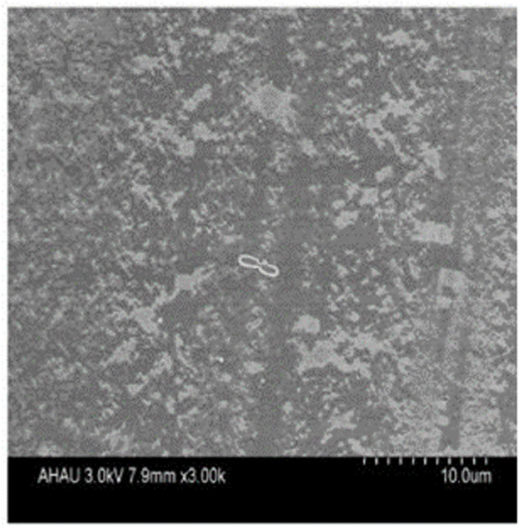

Fig. 5 Inhibitory effect of resveratrol on avian pathogenic Escherichia coli biofilm formation observed using scanning electron microscopy

osmotic pressure, ions, nutrients, and other factors derived from the biological environment. APEC biofilm formation seems to be mostly limited to nutrient depleted media; whereas, avian fecal Escherichia coli (AFEC) are able to form biofilms in both nutrient depleted and replete media [50]. Adhesion and colonization play an important role in biofilm formation [11]. Motility is necessary for the process of colonization, adhesion, and infection by pathogens. E. coli motility includes swimming and swarming. The results of the present study showed that resveratrol inhibited the swimming and swarming motility of APEC in a dose-dependent manner. These results were consistent with those of previous reports [51, 52]. In addition, resveratrol was effective in preventing APEC colonization and adhesion on slide surfaces, which was verified using OM, SEM, and CLSM observations. It was speculated that resveratrol decreased the adhesion of APEC cells by inhibiting their swimming and swarming motility abilities, which in turn would inhibit biofilm formation $[53,54]$.
Crystal violet staining was used to identify the antibiofilm effect of resveratrol on APEC in this study. This technique is semiquantitative, simple, fast, and widely used to detect bacterial biofilms in the laboratory [31, 35]. However, the absorbance readings could only be used to determinate biofilm formation accurately when the readings were taken from a homogeneous bacterial suspension [55].. It is possible that the cells could be unevenly packed or irregularly stuck to a surface, which might affect the absorbance readings. Therefore, the antibiofilm effect of resveratrol on APEC was observed using OM, SEM, and CLSM methods, which could compensate for the limitations of crystal violet staining [33-35].

The combined use of a biofilm inhibitor and an antibiotic causes a certain degree of damage to the biofilm and increases the opportunity for the antibiotic to contact the bacteria in the biofilm, resulting in synergistic antibacterial activity and the destruction of the biofilm $[56,57]$. APEC biofilms on the slides were not destroyed after treatment with florfenicol alone at the MIC $(64 \mu \mathrm{g} /$ $\mathrm{mL}$ ). This might be related to resistance to florfenicol. 


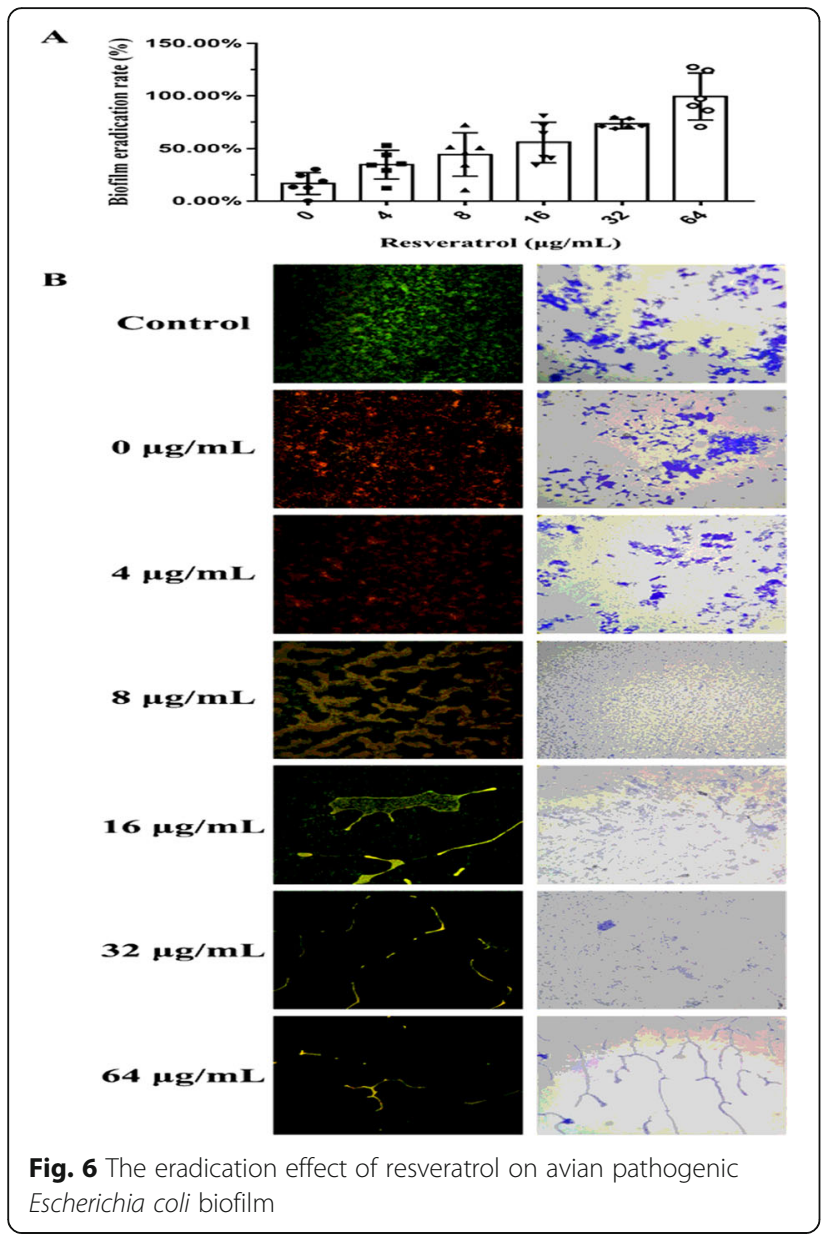

Meanwhile, as the resveratrol concentration increased from $4 \mu \mathrm{g} / \mathrm{mL}$ to $16 \mu \mathrm{g} / \mathrm{mL}$, the APEC biofilm decreased gradually and became sparsely distributed on the slides. There were no large pieces of biofilm on the slides, and the biofilm was destroyed and fell off under treatment with resveratrol at $32 \mu \mathrm{g} / \mathrm{mL}$ and $64 \mu \mathrm{g} / \mathrm{mL}$. Resveratrol at $32 \mu \mathrm{g} / \mathrm{mL}$ inhibited and eradicated APEC biofilms, as observed using SEM, CLSM, and OM. These results are consistent with those obtained by crystal violet staining. The results of motility assay indicated that resveratrol inhibited adhesion and colonization of APEC by inhibiting swimming and swarming motility. Therefore, resveratrol was proven to have a strong eradicating effect on APEC biofilms in vitro. These promising results will lead to further preclinical and in vivo testing of the antibiofilm effects of resveratrol.

\section{Conclusions}

The natural product resveratrol inhibited the formation of APEC biofilms and showed a strong in vitro eradication effect toward APEC biofilms. By contrast, the effect of florfenicol alone on the eradication APEC biofilms was negligible. Furthermore, there was no obviously improved effect of the combination of florfenicol and resveratrol on the eradication of the APEC biofilm. The eradication effect toward biofilms increased gradually with increasing resveratrol concentrations. Interestingly, we also found that resveratrol inhibited the APEC swimming and swarming motility, which might represent the mechanism by which resveratrol inhibits APEC biofilm formation; however, this requires further study. The results suggested that resveratrol could be applied to inhibit and eradicate APEC biofilms and provides a new direction for the prevention and control of diseases caused by APEC.

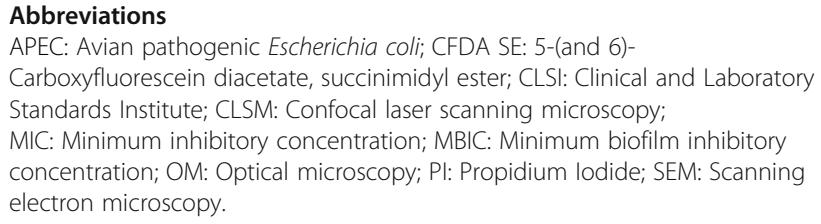

\section{Supplementary Information}

The online version contains supplementary material available at https://doi. org/10.1186/s12917-021-02961-3.

\section{Additional file 1.}

\section{Acknowledgements}

We thank Professor Li for generously donating the wild-type APEC strain. We also thank Mrs. Xiuhong Zhou for helping in the CLSM experiment.

\section{Authors' contributions}

Conceived the manuscript: X. C. RUAN.

Experiment and data processing: X. L. DENG. M. L. TAN. C. B. YU. M. S ZHANG. Y. SUN. N. H. JIANG. Wrote the manuscript: X. L. DENG and M. L. TAN. Revised the manuscript: X. C. RUAN. The author(s) read and approved the final manuscript.

\section{Funding}

This research did not receive any specific grant from funding agencies in the public, commercial, or not-for-profit sectors.

\section{Availability of data and materials}

All data generated or analyzed during this study are included in this published article and its supplementary information files.

\section{Declarations}

All authors have read and approved this version of the article, and due care has been taken to ensure the integrity of the work.

Ethics approval and consent to participate Not applicable.

\section{Consent for publication}

Not applicable.

\section{Competing interests}

The authors declare that they have no competing interests.

Received: 26 March 2021 Accepted: 7 July 2021

Published online: 20 July 2021

\section{References}

1. Barbieri NL, Vorde JAV, Baker AR, Horn F, Li G, Logue CM, et al. FNR regulates the expression of important virulence factors contributing to the 
pathogenicity of avian pathogenic Escherichia coli. Front Cell Infect Microbiol. 2017;7:265.

2. Khatoon Z, McTiernan CD, Suuronen EJ, Mah TF, Alarcon El. Bacterial biofilm formation on implantable devices and approaches to its treatment and prevention. Heliyon. 2018;4(12):e01067.

3. Karatan E, Watnick P. Signals, regulatory networks, and materials that build and break bacterial biofilms. Microbiol Mol Biol Rev. 2009;73(2):310-47.

4. Flemming HC, Wingender J. The biofilm matrix. Nat Rev Microbiol. 2010;8(9): 623-33.

5. Venkatesan N, Perumal G, Doble M. Bacterial resistance in biofilm-associated bacteria. Future Microbiol. 2015;10(11):1743-50.

6. Costerton JW. Bacterial biofilms: a common cause of persistent infections. Science. 1999;284(5418):1318-22.

7. Dakheel MM, Alkandari FAH, Mueller-Harvey I, Woodward MJ, Rymer C. Antimicrobial in vitro activities of condensed tannin extracts on avian pathogenic Escherichia coli. Lett Appl Microbiol. 2020;70(3):165-72.

8. Giaouris E, Heir E, Hebraud M, Chorianopoulos N, Langsrud S, Moretro T, et al. Attachment and biofilm formation by foodborne bacteria in meat processing environments: causes, implications, role of bacterial interactions and control by alternative novel methods. Meat Sci. 2014;97(3):298-309.

9. Lajhar SA, Brownlie J, Barlow R. Characterization of biofilm-forming capacity and resistance to sanitizers of a range of $E$. coli O26 pathotypes from clinical cases and cattle in Australia. BMC Microbiol. 2018;18(1):41.

10. Latif M Jr, May EE. A multiscale agent-based model for the investigation of E. coli K12 metabolic response during biofilm formation. Bull Math Biol. 2018;80(11):2917-56.

11. Mostafavi SKS, Najar-Peerayeh S, Mobarez AM, Parizi MK. Characterization of uropathogenic E. coli O25b-B2-ST131, O15:K52:H1, and CGA: neutrophils apoptosis, serum bactericidal assay, biofilm formation, and virulence typing. J Cell Physiol. 2019;234(10):18272-82.

12. Verstraeten N, Braeken K, Debkumari B, Fauvart M, Fransaer J, Vermant J, et al. Living on a surface: swarming and biofilm formation. Trends Microbiol. 2008;16(10):496-506.

13. Kearns DB. A field guide to bacterial swarming motility. Nat Rev Microbiol. 2010;8(9):634-44.

14. Song YJ, Yu HH, Kim YJ, Lee N-K, Paik H-D. Anti-biofilm activity of grapefruit seed extract against Staphylococcus aureus and Escherichia coli. J Microbiol Biotechnol. 2019;29(8):1177-83.

15. Olszewska MA, Gedas A, Simoes M. The effects of eugenol, transcinnamaldehyde, citronellol, and terpineol on Escherichia coli biofilm control as assessed by culture-dependent and -independent methods. Molecules. 2020:25(11):2641

16. Zhu CF, Zhang M, Tang QL, Yang Q, Li J, He X, et al. Structure and activity of the Camellia oleifera sapogenin derivatives on growth and biofilm inhibition of Staphylococcus aureus and Escherichia coli. J Agric Food Chem. 2019;67(51):14143-51.

17. Vestergaard $\mathrm{M}$, Ingmer $\mathrm{H}$. Antibacterial and antifungal properties of resveratrol. Int J Antimicrob Agents. 2019;53(6):716-23.

18. Demirel MA, Han S, Tokmak A, Ercan Gokay N, Uludag MO, Yildirir Ustun T, et al. Therapeutic effects of resveratrol in Escherichia coli-induced rat endometritis model. Naunyn Schmiedeberg's Arch Pharmacol. 2019;392(12): 1577-89.

19. Surendran Nair M, Ma F, Lau P, Upadhyaya I, Venkitanarayanan K. Inactivation of Escherichia coli 0157:H7 in apple cider by resveratrol and naringenin. Food Microbiol. 2020;86:103327.

20. Nohr-Meldgaard K, Ovsepian A, Ingmer H, Vestergaard M. Resveratrol enhances the efficacy of aminoglycosides against Staphylococcus aureus. Int J Antimicrob Agents. 2018;52(3):390-6.

21. Lee J, Lee DG. Novel antifungal mechanism of resveratrol: apoptosis inducer in Candida albicans. Curr Microbiol. 2015;70(3):383-9.

22. Mohd A, Zainal N, Tan KK, AbuBakar S. Resveratrol affects Zika virus replication in vitro. Sci Rep. 2019;9(1):14336.

23. Zhao XH, Tong WZ, Song X, Jia RY, Li LX, Zou YF, et al. Antiviral effect of resveratrol in piglets infected with virulent pseudorabies virus. Viruses. 2018; 10(9):457.

24. Kolouchova I, Matatkova O, Paldrychova M, Kodes Z, Kvasnickova E, Sigler K et al. Resveratrol, pterostilbene, and baicalein: plant-derived anti-biofilm agents. Folia Microbiol. 2018;63(3):261-72.

25. Kim JR, Cha MH, Oh DR, Oh WK, Rhee JH, Kim YR. Resveratrol modulates RTX toxin-induced cytotoxicity through interference in adhesion and toxin production. Eur J Pharmacol. 2010;642(1-3):163-8.
26. Luo J, Dong BY, Wang K, Cai SQ, Liu T, Cheng X, et al. Baicalin inhibits biofilm formation, attenuates the quorum sensing-controlled virulence and enhances Pseudomonas aeruginosa clearance in a mouse peritoneal implant infection model. PLoS One. 2017;12(4):e0176883.

27. Yu HY, Li QF. Screening biofilm and determination growth biofilm of curve in Escherichia coli. Chin Agri Sci Bull. 2014;30(5):23-7.

28. Patel J, Yin HB, Bauchan G, Mowery J. Inhibition of Escherichia coli 0157:H7 and Salmonella enterica virulence factors by benzyl isothiocyanate. Food Microbiol. 2020;86:103303.

29. Mittal N, Tesfu HH, Hogan AM, Cardona ST, Sorensen JL. Synthesis and antibiotic activity of novel acylated phloroglucinol compounds against methicillin-resistant Staphylococcus aureus. J Antibiot. 2019;72(5):253-9.

30. Khan F, Manivasagan P, Pham DTN, Oh J, Kim SK, Kim YM. Antibiofilm and antivirulence properties of chitosan-polypyrrole nanocomposites to Pseudomonas aeruginosa. Microb Pathog. 2019:128:363-73.

31. Sandasi $\mathrm{M}$, Leonard CM, Viljoen $\mathrm{AM}$. The in vitro antibiofilm activity of selected culinary herbs and medicinal plants against listeria monocytogenes. Lett Appl Microbiol. 2010;50(1):30-5.

32. Zhang ZY, Sun Y, Zheng YD, He W, Yang YY, Xie YJ, et al. A biocompatible bacterial cellulose/tannic acid composite with antibacterial and anti-biofilm activities for biomedical applications. Mater Sci Eng C Mater Biol Appl. 2020; 106:110249.

33. Yin $L, L i$ QW, Xue $M$, Wang ZP, Tu J, Song XJ, et al. The role of the phoP transcriptional regulator on biofilm formation of avian pathogenic Escherichia coli. Avian Pathol. 2019:48(4):362-70.

34. Kumar P, Dev S, Kumar A, Thakur R, Dhar R. Impact of indium doping on the anti-biofilm activity of $\mathrm{ZnO}$ thin films against Escherichia coli and Staphylococcus aureus. Superlattice Microst. 2021;150:106741.

35. Qian WD, Yang M, Li XC, Sun ZH, Li YD, Wang XJ, et al. Anti-microbial and anti-biofilm activities of combined chelerythrine-sanguinarine and mode of action against Candida albicans and Cryptococcus neoformans in vitro. Colloids Surf B Biointerfaces. 2020;191:111003.

36. Lynch AS, Robertson GT. Bacterial and fungal biofilm infections. Annu Rev Med. 2008;59:415-28.

37. Liu Y, Gong QW, Qian XJ, Li DZ, Zeng H, Li YH, et al. Prophage phiv205-1 facilitates biofilm formation and pathogenicity of avian pathogenic Escherichia coli strain DE205B. Vet Microbiol. 2020;247:108752.

38. Rodrigues SV, Laviniki V, Borges KA, Furian TQ, Moraes HLS, Nascimento VP, et al. Biofilm formation by avian pathogenic Escherichia coli is not related to in vivo pathogenicity. Curr Microbiol. 2019;76(2):194-9.

39. Liu CY, Diao YJ, Wang DX, Chen H, Tang Y, Diao YX. Duck viral infection escalated the incidence of avian pathogenic Escherichia coli in China. Transbound Emerg Dis. 2019;66(2):929-38.

40. Kouidhi B, Al Qurashi YM, Chaieb K. Drug resistance of bacterial dental biofilm and the potential use of natural compounds as alternative for prevention and treatment. Microb Pathog. 2015;80:39-49.

41. Abdalla MA, Zidorn C. The genus Tragopogon (Asteraceae): a review of its traditional uses, phytochemistry, and pharmacological properties. J Ethnopharmacol. 2019:250:112466.

42. Chai TT, Tan YN, Ee KY, Xiao J, Wong FC. Seeds, fermented foods, and agricultural by-products as sources of plant-derived antibacterial peptides. Crit Rev Food Sci Nutr. 2019;59(sup 1):S162-77.

43. Lee JH, Park JH, Cho HS, Joo SW, Cho MH, Lee J. Anti-biofilm activities of quercetin and tannic acid against Staphylococcus aureus. Biofouling. 2013;29(5):491-9.

44. Qian WD, Fu YT, Liu M, Wang T, Zhang JN, Yang M, et al. In vitro antibacterial activity and mechanism of vanillic acid against carbapenemresistant Enterobacter cloacae. Antibiotics. 2019;8(4):220.

45. Qian W, Zhang J, Wang W, Wang T, Liu M, Yang M, et al. Antimicrobial and antibiofilm activities of paeoniflorin against carbapenem-resistant Klebsiella pneumoniae. J Appl Microbiol. 2019;128(2):401-13.

46. Kugaji MS, Kumbar VM, Peram MR, Patil S, Bhat KG, Diwan PV. Effect of resveratrol on biofilm formation and virulence factor gene expression of Porphyromonas gingivalis in periodontal disease. APMIS. 2019;127(4):187-95.

47. He ZY, Huang ZW, Zhou W, Tang ZS, Ma R, Liang JP. Anti-biofilm activities from resveratrol against Fusobacterium nucleatum. Front Microbiol. 2016;7:1065.

48. Thakur S, Ray S, Jhunjhunwala S, Nandi D. Insights into coumarin-mediated inhibition of biofilm formation in Salmonella Typhimurium. Biofouling. 2020; 36(4):479-91.

49. Zhang F, Zhu JN, Feng LF. Inhibition analysis of resveratrol against Vibrio parahaemolyticus biofilm based on RNA-Seq technology. Acta Microbiol Sin. 2016;56(5):856-66 
50. Skyberg JA, Siek KE, Doetkott C, Nolan LK. Biofilm formation by avian Escherichia coli in relation to media, source and phylogeny. J Appl Microbiol. 2007;102(2):548-54.

51. Vasavi HS, Sudeep HV, Lingaraju HB, Shyam PK. Bioavailability-enhanced resveramax modulates quorum sensing and inhibits biofilm formation in Pseudomonas aeruginosa PAO1. Microb Pathog. 2017;104:64-71.

52. Chen J, Yu Y, Li S, Ding W. Resveratrol and coumarin: novel agricultural antibacterial agent against ralstonia solanacearum in vitro and in vivo. Molecules. 2016;21(11):1501.

53. Beloin C, Roux A, Ghigo JM. Escherichia coli biofilms. Curr Top Microbiol Immunol. 2008;322:249-89.

54. Wood TK. Insights on Escherichia coli biofilm formation and inhibition from whole-transcriptome profiling. Environ Microbiol. 2009:11(1):1-15.

55. Hu JS, Chen HT, Zhang J, Liu YS, Xu ZW, Zhu L, et al. Advances in the common identification methods of bacterial biofilm. Chin Vet Sci. 2010; 40(11):1194-9.

56. Park SC, Lee MY, Kim JY, Kim H, Jung M, Shin MK, et al. Anti-biofilm effects of synthetic antimicrobial peptides against drug-resistant Pseudomonas aeruginosa and Staphylococcus aureus planktonic cells and biofilm. Molecules. 2019;24(24):4560.

57. Glatthardt T, Campos JCM, Chamon RC, Coimbra TFS, Rocha GA, de Melo MAF, et al. Small molecules produced by commensal Staphylococcus epidermidis disrupt biofilm formation by Staphylococcus aureus. Appl Environ Microbiol. 2019;86(5):e02539-19.

\section{Publisher's Note}

Springer Nature remains neutral with regard to jurisdictional claims in published maps and institutional affiliations.

Ready to submit your research? Choose BMC and benefit from:

- fast, convenient online submission

- thorough peer review by experienced researchers in your field

- rapid publication on acceptance

- support for research data, including large and complex data types

- gold Open Access which fosters wider collaboration and increased citations

- maximum visibility for your research: over $100 \mathrm{M}$ website views per year

At BMC, research is always in progress.

Learn more biomedcentral.com/submissions 